\title{
Histopathological Spectrum of Non-neoplastic and Neoplastic Lesions of Thyroid: A 5-year Prospective Study in a Tertiary Care Hospital
}

\author{
${ }^{1}$ M Padmavathi, ${ }^{2}$ Jyothi A Raj
}

\begin{abstract}
Introduction: Thyroid gland is unique among the endocrine glands in that it can be affected by a wide spectrum of diseases ranging from functional and immunologically mediated enlargements to neoplastic lesions. Thyroid neoplasms represent the most common malignancies of the endocrine system.
\end{abstract}

Aims and objectives: To study the frequency of various thyroid lesions in thyroidectomy specimens and categorize neoplasms based on current World Health Organization (WHO) classification.

Materials and methods: All thyroidectomy specimens received in the Department of Pathology, RajaRajeswari Medical College, Bengaluru, India, for histopathological examination over a period of 5 years, from July 2010 to June 2015, were included in the study.

Results: A total of 211 thyroidectomies were examined in the study. The highest incidence of thyroid lesions was seen in the fourth decade $(n=68,36 \%)$ and showed a female predominance (90\%). Non-neoplastic lesions accounted for 148 cases (70.1\%) and neoplasms accounted for 63 cases (29.9\%). The common non-neoplastic lesions were multinodular goiter (37.2\%) followed by Hashimoto thyroiditis (35.8\%), colloid goiter (16.9\%), and adenomatous hyperplasia (5.3\%). Benign neoplasms (22.2\%) were lower with all cases being follicular adenoma, and malignancies were higher (77.8\%) with papillary carcinoma (58.7\%) as the most common malignancy in our study. Colloid goiter and multinodular goiter were the common features in peritumoral thyroid tissue, followed by Hashimoto thyroiditis.

Conclusion: Thyroid disorders are commonly encountered endocrine diseases. Histopathological examination is the mainstay for definitive diagnosis and management of thyroid neoplasms. Appropriate categorization of neoplasms according to international guidelines is to be followed for diagnostic accuracy.

Keywords: Morphology, Neoplastic, Non-neoplastic, Thyroidectomies.

How to cite this article: Padmavathi M, Raj JA. Histopathological Spectrum of Non-neoplastic and Neoplastic Lesions of Thyroid:

\footnotetext{
${ }^{1}$ District Leprosy Officer, ${ }^{2}$ Professor

${ }^{1}$ Department of Health and Family Welfare Services, Government of Karnataka, Ramanagar Karnataka, India

${ }^{2}$ Department of Pathology, RajaRajeswari Medical College \& Hospital, Bengaluru, Karnataka, India

Corresponding Author: Jyothi A Raj, Professor, Department of Pathology, RajaRajeswari Medical College \& Hospital Bengaluru, Karnataka, India, e-mail: jyoki255@yahoo.co.in
}

A 5-year Prospective Study in a Tertiary Care Hospital. J Med Sci 2017;3(3):63-68.

Source of support: Nil

Conflict of interest: None

\section{INTRODUCTION}

Thyroid diseases are among the commonly encountered disorders in any hospital. They include a vast array of developmental, inflammatory, hyperplastic, and neoplastic lesions. Goiter is a major health concern in many parts of the world. ${ }^{1}$ Thyroid enlargements may be diffuse or nodular, at times causing obvious physiological changes. Nodular lesions comprise those disorders that produce a clinical nodule and consist of non-neoplastic hyperplasias as well as benign and malignant tumors. ${ }^{2}$ From a clinical standpoint, the possibility of neoplastic disease is of major concern in patients who present with thyroid nodules. For most of the thyroid tumors, a diagnosis can be reached by morphologic assessment alone; so, the classification of various histomorphological features is important to categorize the lesions into benign and malignant tumors. Benign thyroid tumors are common, and although cancers are relatively rare, they represent the most common of the endocrine malignancies, accounting for approximately $1 \%$ of all malignancies in the endocrine system. Histological classification of thyroid tumors is essential for further therapy and prognosis. ${ }^{3}$

\section{MATERIALS AND METHODS}

All thyroidectomy specimens received in the Department of Pathology, RajaRajeswari Medical College and Hospital, Bengaluru, India, for histopathological examination were included in the study. After gross examination, bits from the representative areas were processed for morphological study; clinical history, findings, and diagnosis were documented in prepared pro forma along with microscopic findings.

\section{RESULTS}

Of the 211 thyroidectomy specimens received over a period of 5 years $(n=211,0.85 \%)$, non-neoplastic lesions accounted for 148 cases ( $\mathrm{n}=148,70.1 \%$ ) and neoplastic lesions accounted for 63 cases $(n=63,29.9 \%$; Graph 1$)$. 


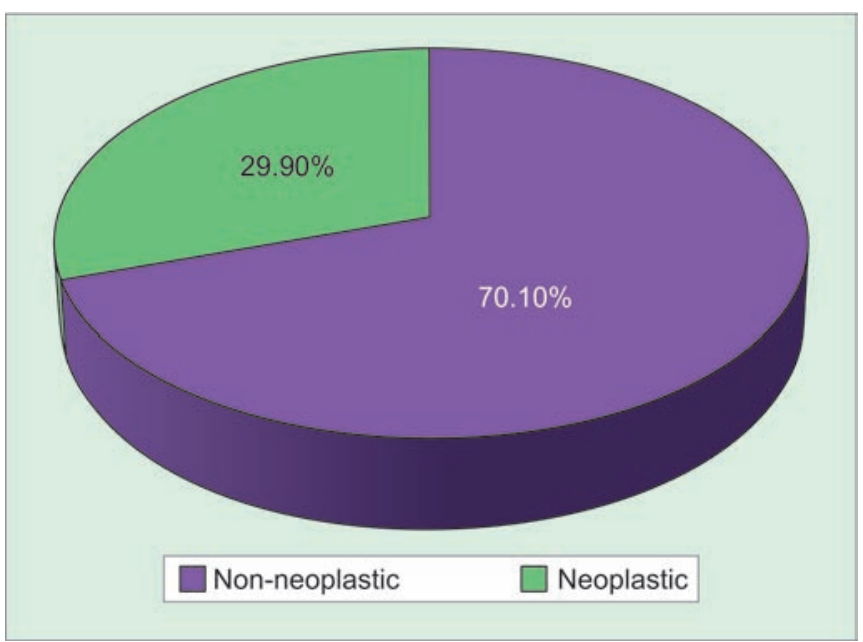

Graph 1: Incidence of non-neoplastic and neoplastic lesions of thyroid $(n=211)$

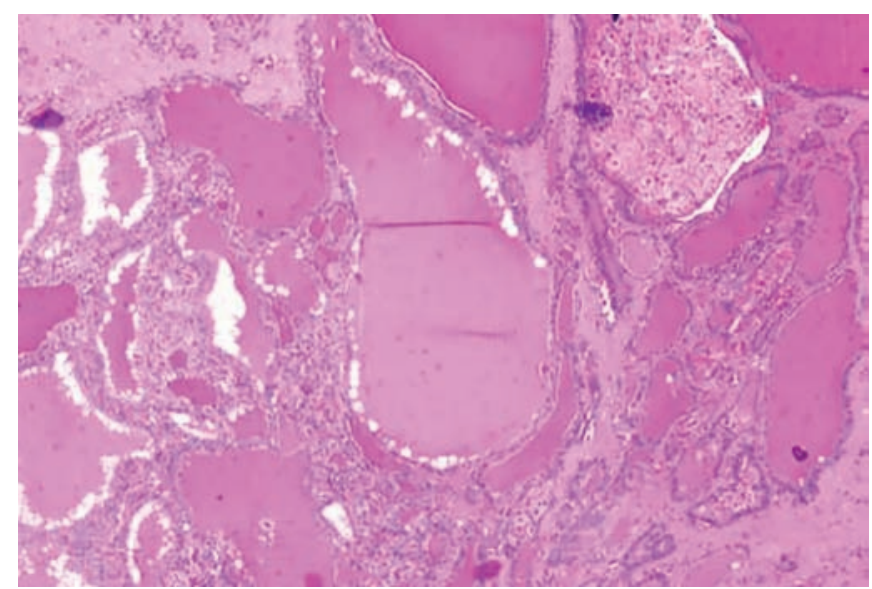

Fig. 2: Multinodular goiter: Photomicrograph of thyroid showing varying sized follicles lined by flattened to cuboidal epithelium filled with colloid. There is scalloping of colloid in few follicles. Areas of fibrosis, inflammatory infiltrate, and macrophages are also seen (hematoxylin and eosin, $4 \times$ )

The most common non-neoplastic lesion was multinodular goiter with 55 cases $(\mathrm{n}=55,37.2 \%)$ (Figs 1 and 2 ) followed by Hashimoto thyroiditis which accounted for 53 cases ( $n=53,35.8 \%$; Figs 3, 4 and Graph 2). Among 63 neoplasms of thyroid, 14 benign neoplasms $(n=14,22.2 \%)$ and 49 cases $(n=49,77.8 \%)$ of malignant neoplasms were reported.

All benign neoplasms were follicular adenomas ( $\mathrm{n}=14$, $22.2 \%$ ), which showed an age predominance in the second to fourth decades of life (Figs 5 and 6). Of the 49 malignant neoplasms, the most common was papillary carcinoma, accounting for 37 cases $(n=37,58.7 \%)$. Other neoplasms reported were seven cases $(n=7,11.1 \%)$ of follicular neoplasms of undetermined significance, two $(n=2,3.2 \%)$ cases of follicular carcinoma, one case each of medullary carcinoma $(\mathrm{n}=1,1.6 \%)$ and anaplastic carcinoma $(\mathrm{n}=1,1.6 \%)$.

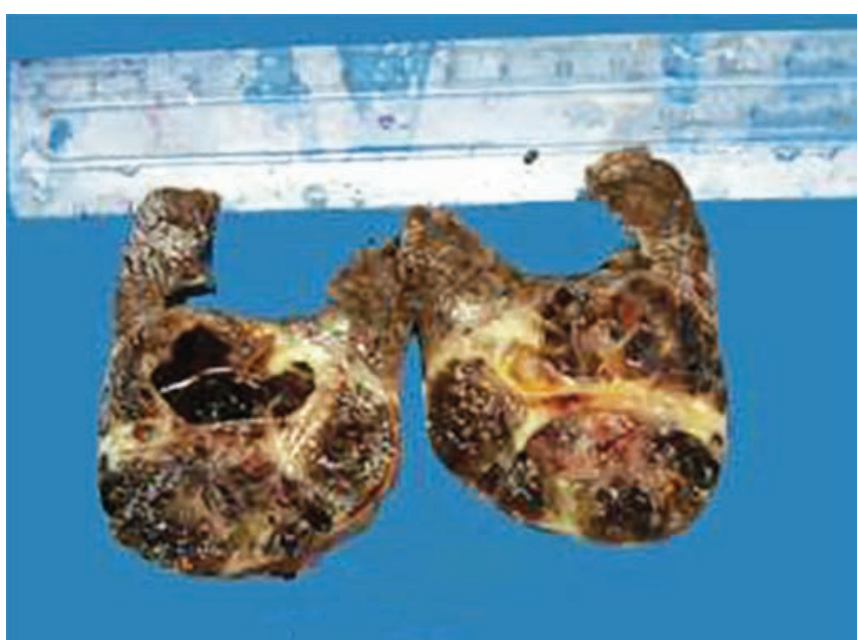

Fig. 1: Multinodular goiter: Cut surface of subtotal thyroidectomy specimen showing enlarged thyroid with multiple nodules separated by fibrous septae and cystic change

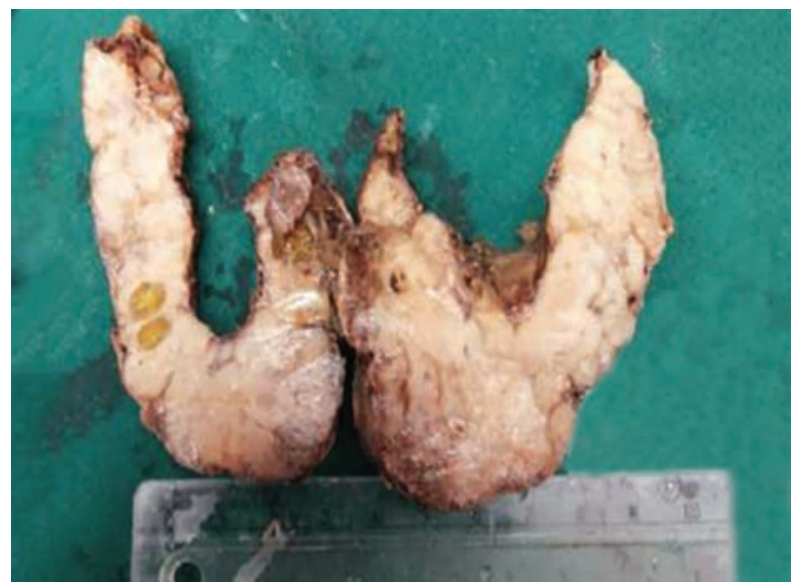

Fig. 3: Hashimoto thyroiditis: Total thyroidectomy specimen showing diffuse symmetrical enlargement of the thyroid gland. Cut surface has a gray white fleshy appearance

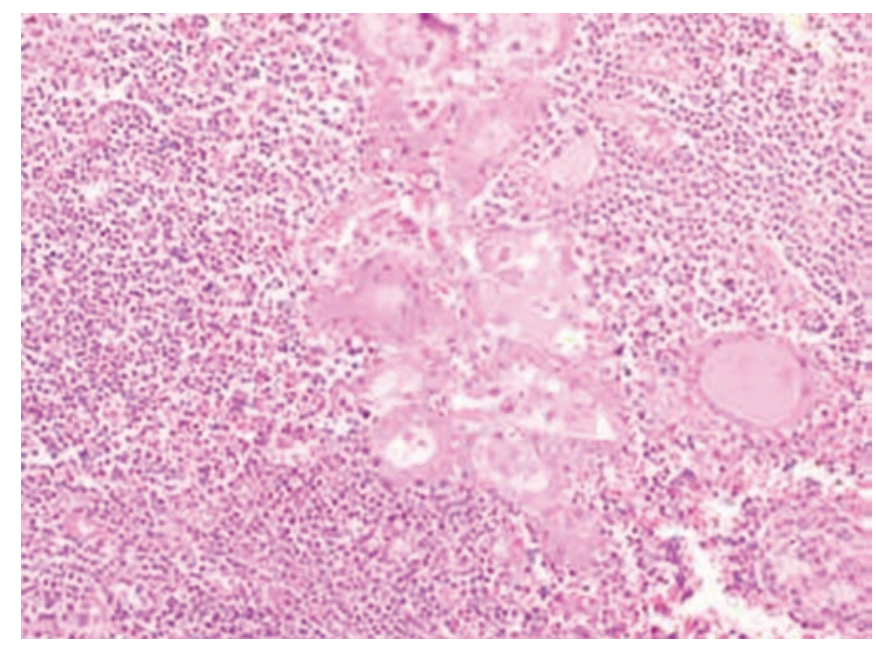

Fig. 4: Hashimoto thyroiditis: Photomicrograph shows destroyed thyroid follicles lined by Hurthle cells and surrounded by dense lymphocytic infiltrate (hematoxylin and eosin, 20x) 


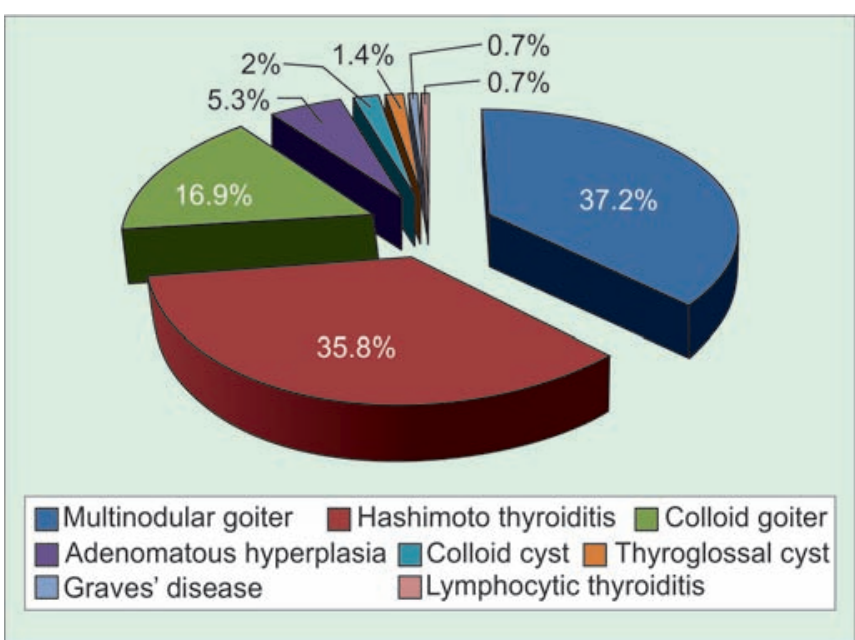

Graph 2: Histomorphological types of non-neoplastic lesions of thyroid

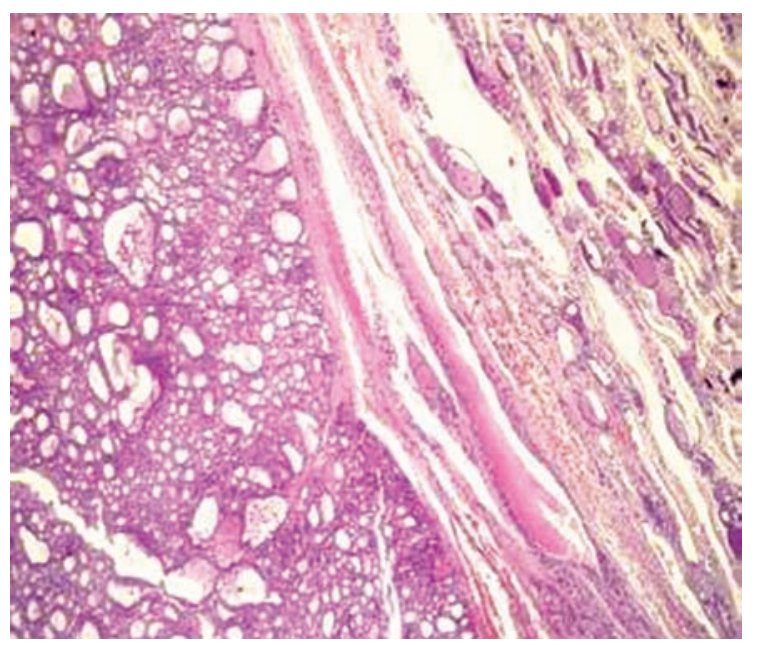

Fig. 6: Follicular adenoma: Photomicrograph showing wellencapsulated tumor composed of varying sized follicles lined by cuboidal epithelium compressing the surrounding thyroid tissue (hematoxylin and eosin, 10x)

Among 37 cases of papillary carcinoma, the most common was follicular variant $(\mathrm{n}=23,62.1 \%)$, followed by classical papillary carcinoma ( $\mathrm{n}=11,29.7 \%$; Graph 3; Figs 7 and 8).

Papillary microcarcinoma $(n=2,5.5 \%)$ was seen in two cases. According to the WHO updated classification, it is defined as tumor smaller than $1 \mathrm{~cm}$. These microcarcinomas are sometimes multifocal in the same lobe and may also involve the other lobe.

Following extensive histopathological evaluation of the resected specimens, various morphologic patterns were noted in the thyroid tissue surrounding the tumors. Morphology of peritumoral thyroid was significant in 25 cases (Graph 4): 6 cases showed colloid goiter, 5 had multinodular goiter, and Hashimoto thyroiditis was seen around 4 tumors. Multicentric papillary carcinoma was seen in four cases. Hashimoto thyroiditis and multicentric

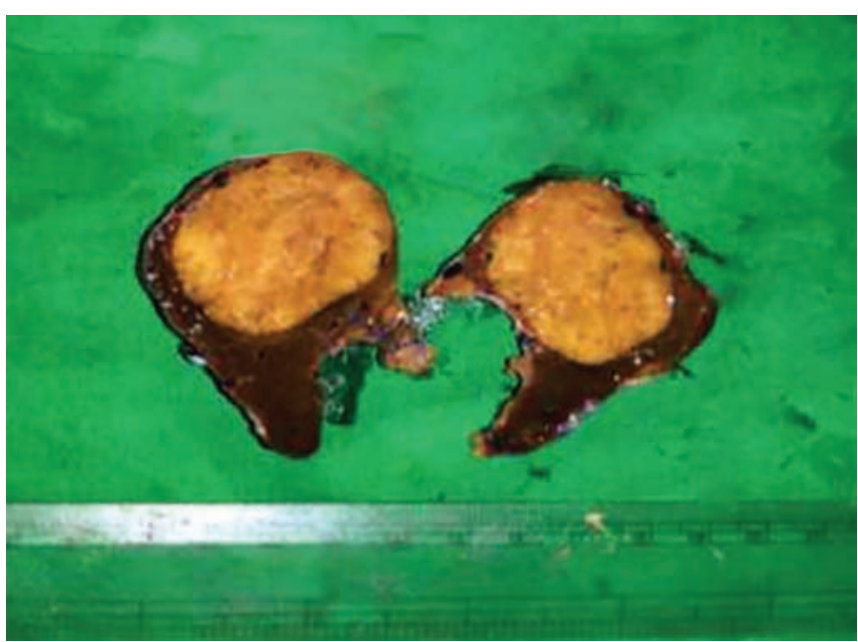

Fig. 5: Follicular adenoma: Cut surface of hemithyroidectomy specimen, showing a well-circumscribed gray white nodule, distinct from the surrounding thyroid tissue

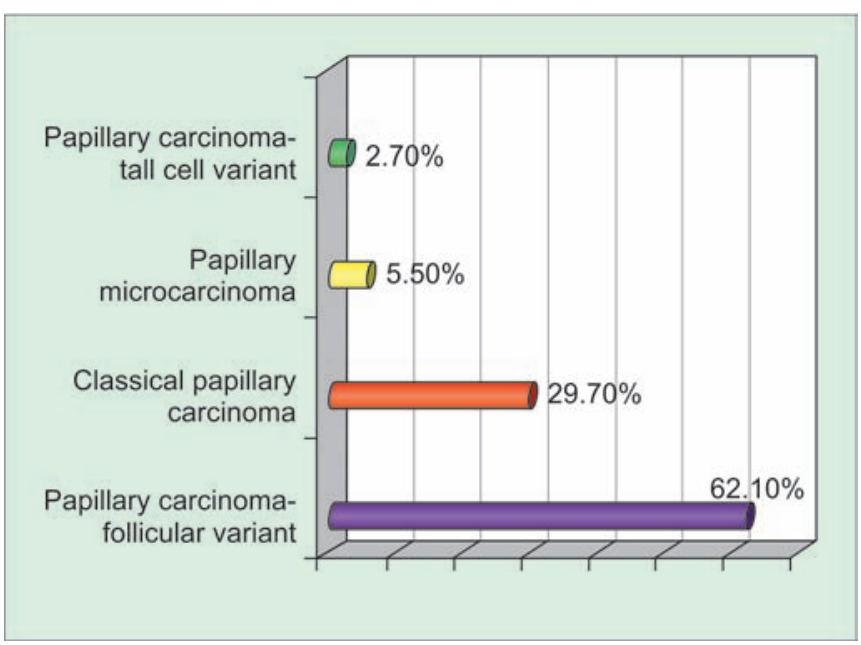

Graph 3: Variants of papillary carcinoma thyroid $(n=37)$

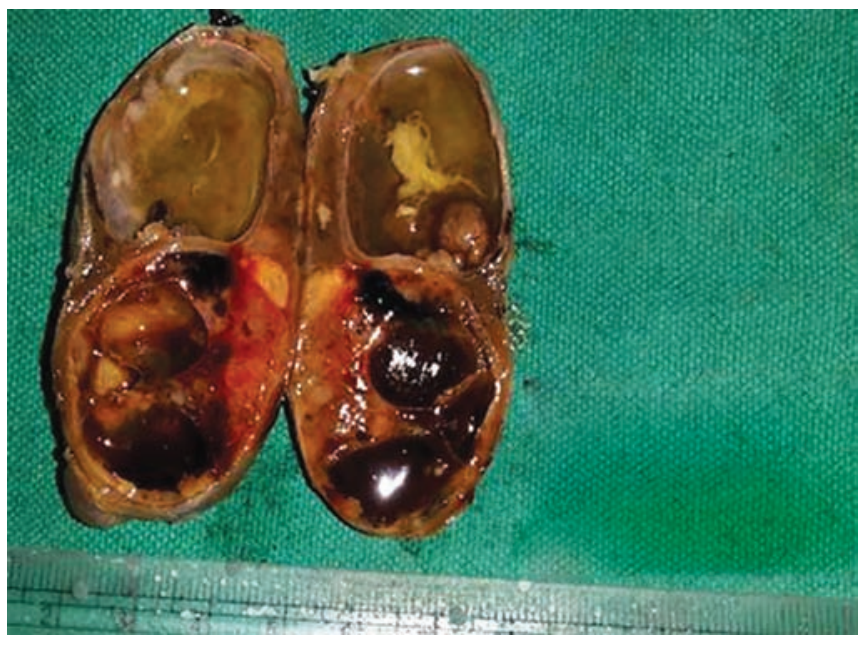

Fig. 7: Papillary carcinoma thyroid hemithyroidectomy specimen showing cysts with a mural nodule above and gray brown solid areas below 


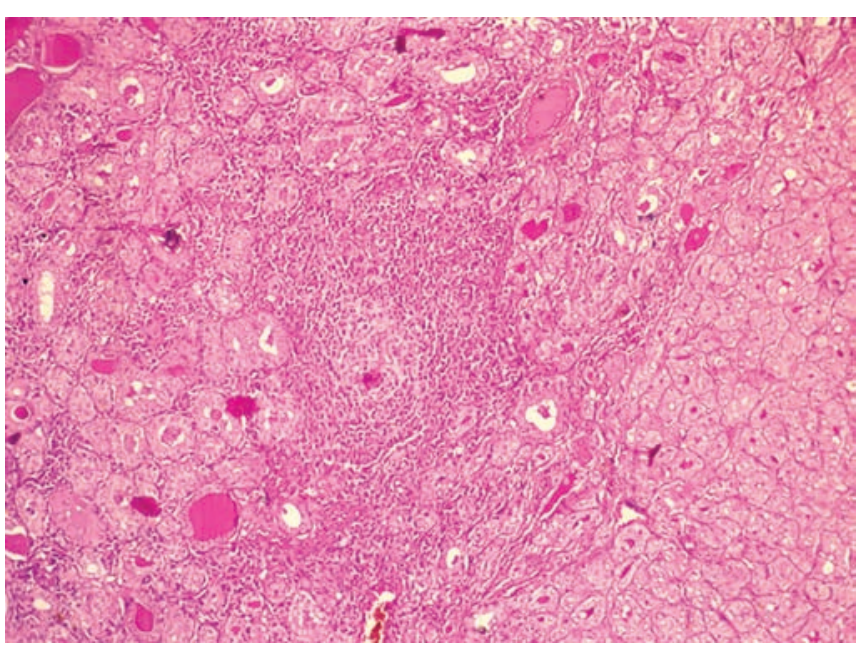

Fig. 8: Papillary carcinoma thyroid follicular variant: Photomicrograph showing neoplastic follicles with nuclear features of papillary carcinoma. Peritumoral thyroid showed features of Hashimoto thyroiditis (hematoxylin and eosin, 10x) tumor were together seen in two cases. One case each of multinodular goiter with Hashimoto thyroiditis and colloid goiter with multicentric tumor were also noted. Hurthle cell nodule and Hashimoto thyroiditis with Hurthle cell nodule were noted in one case each. Inflammatory infiltrate, psammoma bodies, and calcification were other features seen in the peritumoral thyroid tissue (Figs 8 to 10).

\section{DISCUSSION}

The thyroid gland is unique among endocrine organs in many ways. ${ }^{1}$ It is the largest of all endocrine glands and by virtue of its superficial location is the only one, i.e., amenable to direct physical examination and biopsy. ${ }^{4}$ The gland develops from an evagination of the developing pharyngeal epithelium that descends as part of the

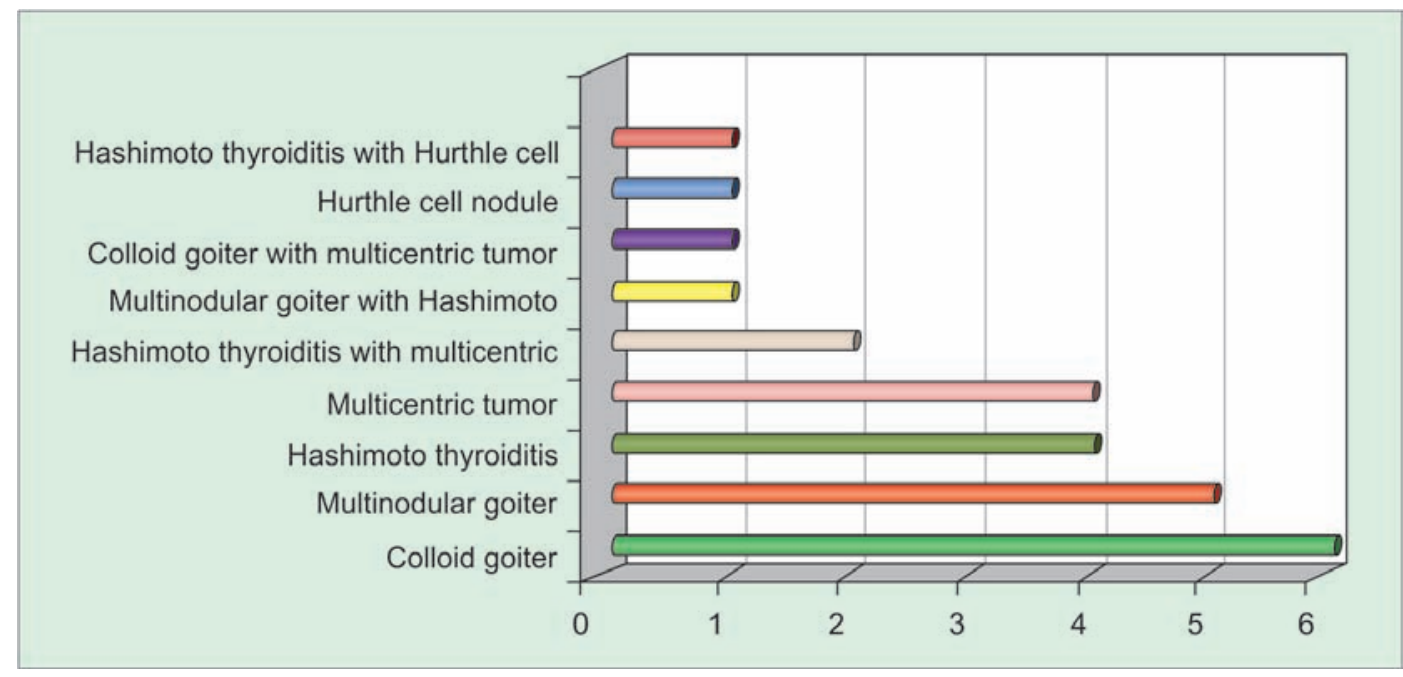

Graph 4: Peritumoral morphology in thyroid neoplasms

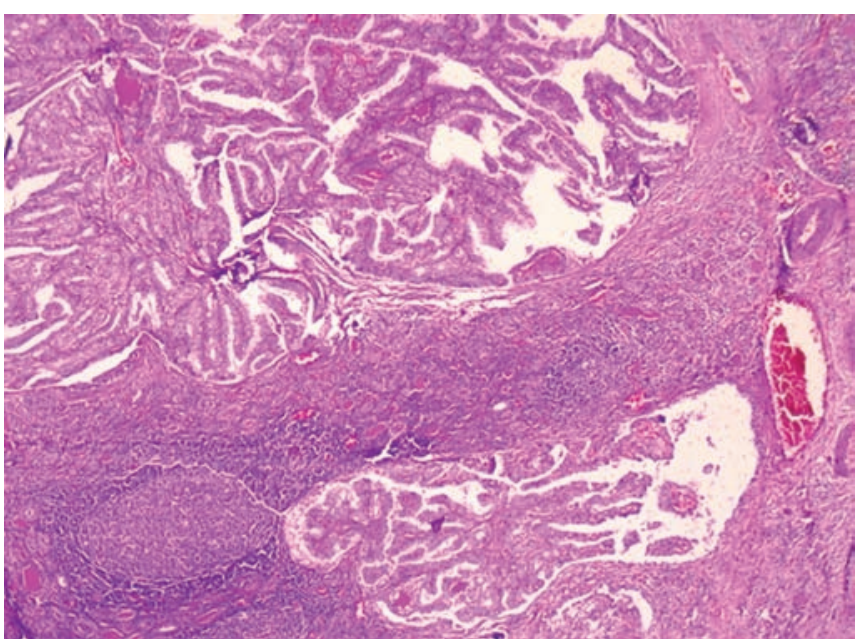

Fig. 9: Papillary carcinoma thyroid: Photomicrograph shows multicentric tumor with papillary pattern. Surrounding thyroid tissue shows features of Hashimoto thyroiditis. Psammoma bodies are noted in the tumor and surrounding thyroid tissue (hematoxylin and eosin, 4×)

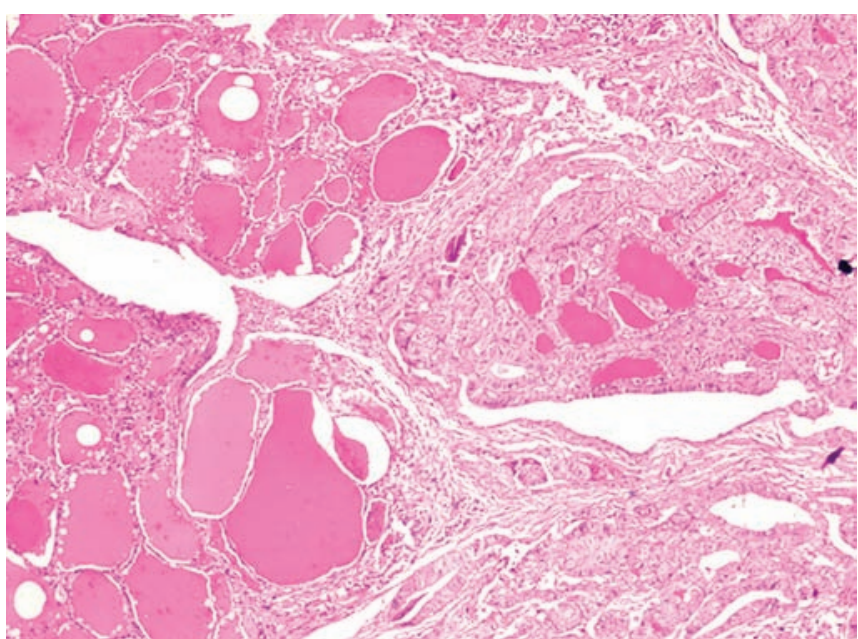

Fig. 10: Papillary carcinoma thyroid: Photomicrograph shows a focus of papillary carcinoma in the lower right hand corner with features of multinodular goiter in the surrounding thyroid (hematoxylin and eosin, 10x) 
thyroglossal duct from foramen cecum at the base of tongue to its normal position in the anterior neck. ${ }^{1}$

The functional units of the thyroid gland are the follicles, which are lined of a single layer of cuboidal epithelial cells bound by a basement membrane. It is divided by thin fibrous septae into lobules composed of 20 to 40 evenly dispersed follicles filled with thyroglobulin, the storage form of thyroxine (T4) and triiodothyronine (T3). ${ }^{5}$

Thyroid diseases are associated with hyperthyroidism, hypothyroidism, and mass lesions. From a clinical standpoint, the possibility of neoplastic disease is of major concern in patients who present with thyroid nodules. ${ }^{1}$

Benign thyroid tumors are common, and although cancers are relatively rare, they represent the most common malignancies of the endocrine system. Thyroid tumors account for approximately $1 \%$ of all malignancies in the endocrine system. The WHO published its second edition on histological classification of thyroid tumors in 2004. Classification of thyroid tumors is essential for further therapy and prognosis. ${ }^{3}$

Papillary carcinomas are the most common, accounting for nearly $85 \%$ of primary thyroid malignancies. Benign lesions like multinodular goiter and Hashimoto thyroiditis are commonly associated with papillary carcinoma thyroid. Papillary carcinoma and thyroiditis are both common conditions, the possibility of coincidental coexistence is more likely than an etiologic relationship. ${ }^{2}$ Recently, two independent studies have shown high prevalence of RET/papillary thyroid carcinoma (PTC) in benign thyroid tissue affected by Hashimoto thyroiditis. It has been suggested that immunohistochemical detection of RET/PTC can be helpful in early diagnosis of PTCs. ${ }^{6}$ Activating RAS mutations occur in a few hyperplastic nodules. Observations such as monoclonal origin of some hyperplastic nodules, occurrence of cytogenetic abnormalities, aneuploidy, and oncogenic mutations indicate that hyperplastic nodules over a long time may become neoplastic. ${ }^{7}$

Pradeepkumar et $\mathrm{al}^{8}$ studied a large number of cases ( $n=342$ ) and reported the highest incidence of thyroid lesions in the age group between 26 and 30 years (68\%). In the present study, the highest incidence of thyroid lesions was seen in the fourth decade ( $n=68,36 \%$ ). Maximum number of cases was seen in the age group between 20 and 49 years, similar to the findings in the study by Ramesh and Ramu. ${ }^{9}$

Most thyroid lesions show a female predominance and this fact was corroborated in our study as well as in the studies by Ramesh and Ramu, ${ }^{9}$ Ijomone et al, ${ }^{10}$ and Ahmed et al. ${ }^{11}$

In our study, non-neoplastic lesions accounted for 148 cases ( $\mathrm{n}=148,70.1 \%$ ) and neoplastic lesions accounted for 63 cases $(n=63,29.9 \%)$. Similar incidence was reported by Albasri et $\mathrm{al}^{12}$ with $72.3 \%$ non-neoplastic lesions and $27.7 \%$ neoplastic lesions in their study. Higher incidence of neoplasms was reported by Salama et $\mathrm{al}^{13}$ in a study based in Saudi Arabia and by Pradeepkumar et $\mathrm{al}^{8}$ in their study from coastal Karnataka.

The relative incidence of benign and malignant neoplasms in our study was comparable with that reported by Salama et al. ${ }^{13}$ The incidence of benign neoplasms was lower and malignancies were higher in our study compared with that reported by Patil et al. ${ }^{14}$

Incidence of follicular adenoma and papillary carcinoma was comparable in the studies done by Salama et $\mathrm{al}^{13}$ Bharathidhasan et $\mathrm{al}^{15}$ and the present study. Incidence of follicular carcinoma in our study was similar to that reported by Salama et al. ${ }^{13}$ Bharathidhasan et $\mathrm{a}^{15}$ reported a higher incidence of follicular carcinoma.

One case each of anaplastic carcinoma, medullary carcinoma, and carcinoma metastatic to thyroid was reported in our study.

Seven neoplasms were reported as follicular tumor of uncertain malignant potential in our study. These tumors were extensively sampled and sections studied to look for definite capsular invasion. Blunt end breaks were noted in the capsule, which could not be categorically called capsular invasion. These were classified as follicular tumor of uncertain malignant potential, in keeping with the WHO guidelines. No such cases were reported in other studies.

In a study done by Konturek et $\mathrm{al}^{16}$ with a total sample size of 7545, 106 cases of papillary carcinoma showed Hashimoto thyroiditis in the surrounding thyroid tissue.

Campos et $\mathrm{al}^{17}$ studied 315 thyroidectomies: 11 of the 41 cases of papillary carcinoma showed concurrent Hashimoto thyroiditis (26.8\%). Praveen Kumar and $\mathrm{D}^{\prime}$ Souza ${ }^{18}$ reported 15 thyroid malignancies with multinodular goiter in the surrounding thyroid. Hanumanthappa et $\mathrm{al}^{19}$ in their study of 100 cases of multinodular goiter found 10 concurrent malignancies in the adjacent thyroid. Imad et $\mathrm{al}^{20}$ reported 9 malignancies in 80 cases of multinodular goiter.

Among the 63 neoplasms in our study, 25 cases $(n=25)$ showed significant peritumoral morphology. Of these, colloid goiter was noted in surrounding thyroid in six cases (24\%), multinodular goiter in five cases (20\%), and Hashimoto thyroiditis in four cases (16\%). Multicentric tumor foci were seen in four cases (16\%). Hashimoto thyroiditis and multicentricity were together noted in two cases $(8 \%)$.

\section{CONCLUSION}

Thyroid disorders are commonly encountered endocrine diseases. Although noninvasive techniques like aspiration cytology provide a diagnosis in most, the ultimate 
answer often rests with histopathological examination of thyroidectomies, which forms the mainstay for a definitive diagnosis. Non-neoplastic thyroid lesions form the most common category following morphologic examination. Thorough gross and microscopic evaluation of thyroidectomies is mandatory even for non-neoplastic lesions as they sometimes harbor neoplasms. Management of thyroid neoplasms depends on their histopathological type. Morphologic features, such as size, capsule, and/ or vascular invasion, are important for prognostication. Appropriate categorization of neoplasms according to international guidelines, like $\mathrm{WHO}$, is to be followed not only for diagnostic accuracy but also to follow a uniform reporting pattern and to rightly convey the microscopic findings to the treating clinician.

\section{REFERENCES}

1. Maitra, A. The endocrine system. Chapter 24. In: Mitchell R, Kumar V, Abbas A, Fausto N, Aster J. editors. Robbins and Cotran pathologic basis of disease. 8th ed. Philadelphia (PA): Saunders Elsevier; 2011. p. 164-165.

2. Baloch, ZW.; Livolsi, VA. Pathology of thyroid and parathyroid disease. Chapter 13. In: Mills SE, Carter D, Greenson JK, Oberman HA, Victor R, Stoler MH, editors. Sternberg's diagnostic surgical pathology. Vol. 1. 4th ed. Philadelphia: Lippincott Williams and Wilkins; 2004. p. 562-569.

3. DeLellis, RA.; Williams, ED. Thyroid and parathyroid tumours. Chapter 2. In: DeLellis RA, Lloyd RV, Heitz PU, Eng $C$, editors. World Health Organisation classification of tumours, pathology and genetics, tumours of endocrine organs. Lyon: IARC Press; 2004. p. 49-52.

4. Carcangiu, ML.; DeLellis, RA. Thyroid gland. Chapter 6. In: Damjanov I, James L, editors. Anderson's pathology. Vol. 2. 10th ed. St. Louis (MO): Mosby; 1996. p. 1943-1979.

5. Young, B.; Lowe, JS. The endocrine gland. Chapter 17. In: Young B, Lowe JS, Stevens A, Heath JW, editors. Wheater's functional histology. 6th ed. Philadelphia (PA): Elsevier; 2014. p. 323-326.

6. Baloch, ZW.; Livolsi, VA. The thyroid gland. Chapter 42. In: Silverberg SG, DeLellis RA, Frable WJ, Livolsi VA, Wick MR, editors. Silverberg's principles and practice of surgical pathology and cytopathology. Vol. 2. 4th ed. London: Churchill Livingstone, Elsevier; 2006. p. 2127-2132.
7. Rosai, J. Thyroid gland, Chapter 9. In: Rosai J, editor. Rosai and Ackerman's surgical pathology. 10th ed. St. Louis (MO): Elsevier; 2005. p. 515-568.

8. Pradeepkumar NS, Singh R, Joseph NM. Emerging trends in thyroid diseases in tsunami hit coastal areas of Puducherry and Cuddalore, India. J Evol Med Dent Sci 2012 Nov;1(5):857-863.

9. Ramesh VL, Ramu S. Study of distribution of thyroid lesions in a hospital. Int J Sci Res 2014 Dec;3(12):2441-2443.

10. Ijomone EA, Duduyemi BM, Udoye E, Nwosu SO. Histopathological review of thyroid diseases in Southern Nigeria-a ten-year retrospective study. J Med Med Sci 2014 Jun;5(6):127-132.

11. Ahmed Z, Chaudhary R, Umaru N. Study of prevalence of thyroid lesions in coastal region of Karnataka. J Evol Med Dent Sci 2013; 2(36):6995-7002.

12. Albasri A, Sawaf Z, Hussainy AS, Alhujaily A. Histopathological patterns of thyroid disease in Al-Madinah region of Saudi Arabia. Asian Pac J Cancer Prev 2014 Jul;15(14): 5565-5570.

13. Salama SI, Abdullah LS, Al-Qahtani MH, Al Maghrabi JA. Histopathological pattern of thyroid lesions in western region of Saudi Arabia. New Egypt J Med 2009 Jun;40(6):580-585.

14. Patil RS, Nimbal NV, Pratima S, Sreekantha, Remya. Histopathological study of thyroid lesions. Int J Pharma Bio Sci 2013; 4(4):1003-1020.

15. Bharathidhasan I, Goneppanavar M, Dhaka RS. Changing trends in the incidence of thyroid lesions in coastal regions of South India. Int J Health Sci Res 2015 Jun;5(6):134-141.

16. Konturek A, Barczynski M, Wierzchowski W, Nowak W. Coexistence of papillary thyroid cancer with Hashimoto thyroiditis. Langenbecks Arch Surg 2013 Mar;398(3):389-394.

17. Campos LAAF, Picado SM, Guimaraes AV, Ribeiro DA, Dedivitis RA. Thyroid papillary carcinoma associated to Hashimoto's thyroiditis. Braz J Otorhinolaryngol 2012 Nov-Dec;78(6):77-80.

18. Praveen Kumar K, D'Souza C. The incidence of thyroid carcinoma in multinodular goiter: retrospective analysis in a Medical College Hospital. Int J Biomed Res 2014; 5(2):90-91.

19. Hanumanthappa MB, Gopinathan $S$, Suvarna R, Rai D, Shetty G, Shetty A, Shetty B, Shetty N. The study of malignancy in multinodular goiter: A prospective study at a tertiary academic centre. J Clin Diagn Res 2012 Apr;6(2):267-270.

20. Imad S, Israr M, Ali M. Frequency of malignancy in multinodular goiter: a review of 80 cases of multinodular goiter. Pak J Surg 2013; 29(1):9-12. 